\title{
Pharmacy Faculty Burnout: Cause for Concern that Requires Our Support and Use of Best Evidence
}

Shane P. Desselle, RPh, PhD, FAPhA ${ }^{1}$; Patricia L. Darbishire, PharmD²; Brooke H. Clubbs, EdD ${ }^{3}$

${ }^{1}$ Touro University California College of Pharmacy; ${ }^{2}$ Purdue University College of Pharmacy; ${ }^{3}$ Southeast Missouri State University

\begin{abstract}
Recent attention has been afforded to the concept of burnout and other quality of worklife issues among pharmacy faculty, underscoring the importance of organizational culture, citizenship, collegiality, and support. Support comes from the larger academic institution, the college/school, and individual colleagues. Evidence points to reassurance of worth, guidance, and positive affirmation as being among the most salient factors in mitigating burnout of faculty, who are caught in the midst of increasing demands and higher administrative burdens. A supportive culture that reassures worth of individual faculty is not a unidimensional typology, but rather, is one that permeates through all components of a multifaceted and strong culture that encourages citizenship. There is a growing body of research and evidence on faculty burnout and related factors. This commentary calls for the use of such evidence in guiding policies, creating mentoring programs, and carrying out daily activities in much the same manner that scholars use the best available evidence in their own specific lines of inquiry in teaching and research.
\end{abstract}

Keywords: faculty, burnout, quality of worklife, organizational culture

\section{The Increasing Complexities and Responsibilities of Academic Life}

Jobs of the professoriate are notoriously overloaded with work and riddled with stress. Budget reductions diminish support staff and other resources, adding administrative tasks to the growing list of academic responsibilities., ${ }^{1,2}$ Meanwhile, scholarship, teaching, and creative engagement demands remain the same. These additional administrative burdens can negatively affect productivity, salary, tenure, promotion, and other organizational rewards. ${ }^{3}$

Faculty generally respond by increasing the number of hours worked. A report in the Chronicle of Higher Education suggests that faculty work an additional 'shift' by returning to their work in the evenings, on weekends, and during holidays and vacation. ${ }^{4}$ This makes academic careers less attractive than they used to be, and jeopardizes commitment to the professoriate. ${ }^{5}$ Gormley and Kennerly found that perceived work climate, created in part by administrators' support and peer collegiality, moderates the effects of role ambiguity and overload on continuance commitment. ${ }^{6}$

Faculty might see greater attention to quality of worklife issues in various documents, such as strategic plans and faculty handbooks; however, those are often in the context of desired behaviors and explicit demands, perhaps without adequate focus on issues like vitality of constituent faculty and specific attention to issues like burnout, which can result from overwork and depersonalization. One of the authors of this paper was sad, yet also bemused, during the past two Christmas

Corresponding author: Shane P. Desselle, RPh, PhD, FAPhA

Professor of Social/Behavioral Pharmacy

Touro University California College of Pharmacy

Phone: 918-892-1168; Email: shane.desselle@tu.edu days upon receiving numerous work-related emails with not only an inquiry, but an expectation of a very prompt and extended reply. It was a reminder that in addition to the fact that we need a bit of time to recharge, we also need to follow the evidence about comportment with our colleagues. We typically embrace evidence from our respective scientific disciplines; however, there is likewise much evidence on burnout and a related constellation of factors to which we also should pay close attention. The remainder of this paper shares some recent evidence about burnout within and outside of pharmacy academia, describes some ramifications of burnout, and describes salient research on where our communications with one another play a momentous role. This is placed within the context of organizational culture and citizenship behaviors, two factors just beginning to receive more attention in the pharmacy literature. It concludes with referral back to our need to rely on evidence from quality of work life studies and a call for additional research in this area.

\section{Presence, Measurement, and Ramifications of Burnout among Faculty}

Work environment issues are especially salient in pharmacy, given the academy's emphasis on faculty recruitment, wellbeing, and retention. A study of pharmacy practice faculty in the United States (U.S.) reported significant burnout, primarily due to emotional exhaustion. ${ }^{7}$ Specifically, emotional exhaustion was identified in $41 \%$ of participants and was higher among women and assistant professors. Burnout also was even higher among those who were without a formal mentor. The authors concluded that large numbers of U.S. pharmacy practice faculty members are suffering from burnout, corroborating studies among physician faculty noting burnout among those with heavy patient care responsibilities. Prescott argued further that pharmacy practice faculty are prone to burnout due to the mismatch in training versus expectations for faculty performance. ${ }^{8}$ This finding corroborates similar evidence from other academic-based health professions. Balancing 
myriad roles from varied stakeholders can result in an untenable work environment. ${ }^{9}$ Among faculty in general (outside of pharmacy), recent evidence suggests a nearly doubling of emotional exhaustion scores from a separate cohort of faculty compared to 15 years previously. ${ }^{10}$

The ramifications of burnout are many, including lack of productivity, desire for a job or career change, generally negative outlook, and intellectual self-doubt. ${ }^{11}$ Intellectual selfdoubt can render a faculty member unable to rejuvenate, affecting their quality of teaching and impeding their prospects for collaboration. This in turn may lead to scholarly anomie, or a decay in the beliefs that the work of the professoriate is even necessary. Feelings of worthlessness, frustration, and lack of purpose can be infectious, particularly in the absence of a positive climate and strong leadership. ${ }^{12}$

In addition to organizational factors, there is the human factor and hope for well-being of our peers, colleagues, and friends. Lee et al. suggest that the responses from one particular item on the Maslach Burnout Inventory (MBI), "I feel emotionally drained from my work", can be predictive of faculty burnout and correlates with cynicism toward colleagues, students, and patients. ${ }^{13,14}$ In 2009, Bruce recognized the deleterious effects of stress and burnout among pharmacy faculty, and made recommendations to maintain personal health, build strong social networks, strive for clear role expectations, self-reflect, improve time management, and participate in a mentoring program, when possible. ${ }^{15}$

\section{A Call to Mitigate Burnout in Pharmacy Academia Through the Use of Effective Communication}

More recently, Darbishire et al. issued a call for the pharmacy academy to address faculty burnout. ${ }^{16}$ They emphasized that burnout is a deterrent to the goals of the American Association of Colleges of Pharmacy (AACP), which include enriching the student application pipeline and painting a positive and robust picture of pharmacy as a career. They indicated a need to emphasize faculty wellness in concert with student wellness. They implored institutions to evaluate factors associated with burnout among their constituent faculty and called for those in supervisory positions to openly discuss burnout potential and develop plans to meet individual needs. The authors noted that an individualized approach might promote vitality and ensure that responsibilities align with the position. They also stressed the need for mentoring and faculty renewal programming.

The recommendations by Darbishire et al. are corroborated by results on faculty burnout outside of pharmacy. In an analysis of burnout across disciplines, Clubbs found that among several variables, the most reliable in mitigating faculty burnout was perception of institutional support. ${ }^{10}$ Her measure of institutional support employed a multi-item scale first used in pharmacy, and indicative of general support for teaching scholarship, and service; appreciation for extra effort; consideration of individual faculty goals and values; provision of adequate resources; and encouragement from the department chair and the dean. ${ }^{17} \mathrm{~A}$ qualitative component of Clubbs' research found that the social provisions of "reassurance of worth" and "guidance" were also very important factors in mitigating burnout, and part of a supportive culture propagated by administrators and faculty colleagues, alike. Indeed, providing supportive feedback to others has long been recognized as one of the most powerful deterrents to burnout and other deleterious work and personal outcomes. ${ }^{18}$

\section{Effective Communication More Common in the Midst of Health Organizational Cultures and Citizenship}

Indeed, a supportive culture is one created by the entire organization, not just its leaders. Some might mistake "climate" for "culture" where the former is more indicative of the current "mood" and can be swayed even by one individual or one policy change. In contrast, "culture" is enduring, and indicative of how things are done in an organization. For example, a new chair or a new dean, or even one memorandum from an administrator or colleague, can affect climate; however, it takes the contributions of many, and over an extended period of time, to affect culture. ${ }^{19}$ Research in academic pharmacy suggests that culture is multidimensional, rather than typological. ${ }^{20}$ Thus, a supportive culture in academia is one that permeates various facets or dimensions of the organization.

Careful consideration must be given to actions that affect the organization's culture. These include even "the little things" that may seem trivial, but which eventually become engrained. Fabio et al. discuss promoting gratitude throughout an organization, which reduces negative emotions and enhances organizational health. ${ }^{21}$ While not studied specifically, the reduction in negative stressors and the reassurance of worth spawned through gratitude can be an important tool to mitigate burnout among faculty. Bloch examined cultures of academia, noting that expressions of gratitude can buffer exhaustion that comes from the kind of competitiveness that damages social bonds, as measured through interviews of faculty representing various disciplines that codified how faculty manage emotions that manifest from the "mood" within their respective academic departments. ${ }^{22}$ Expressing gratitude can be one of many acts of citizenship behavior that manifest from a collegial environment. Citizenship behaviors are not required in one's job description yet generally make the workplace environment much more pleasant and productive. ${ }^{23}$

The concept of citizenship has received increasing attention from AACP. A recently appointed task force underscored its importance on well-being and discussed the need to promote an environment where citizenship is the norm. ${ }^{24}$ While only intimated and not studied directly, it appears the presence of collegiality and routine citizenship behaviors are important deterrents in combating faculty burnout. Demonstrating gratitude and being collegial not only makes us good colleagues, but good people. 
Poor citizenship and lack of gratitude are often largely a function of inadequate communication emanating from weak organizational cultures. ${ }^{25}$ Effective, transparent communication is vital at all levels of any organization; however junior and/or new faculty may be especially prone to the deleterious effects of mixed messaging. ${ }^{26}$ Faculty productivity, vitality, and mitigation of untoward work outcomes, such as burnout, begin with a successful onboarding process. ${ }^{27}$ Academic supervisors should provide clear communication of goals and availability of resources, and keep their word on promises beyond the contract offer. A faculty's contract typically will describe primary responsibilities in return for salary and other benefits. However, new (and returning) faculty are also at least verbally given other assurances, such as those related to the teaching environment, their teaching load, staff support, service requirements, and available resources. Assurances of these type much be kept, and failure to do so results in what is called psychological contract breach. ${ }^{28}$ Psychological contract breach early in an employee's career can initiate a cascade of long-lasting depersonalization in an emotionally exhausting environment. ${ }^{29}$

Much responsibility falls to academic chairs. Chairs should develop effective coping mechanisms for themselves as well, lest they suffer from burnout. ${ }^{30}$ The expectation is high, as chairs must perform transparent, concrete actions in support of their faculty while assisting other administrators in carrying out organizational policy. ${ }^{31}$ As advocates for clinical/non-tenure track faculty with multiple supervisors, chairs must ensure optimal communication. ${ }^{32}$ Perhaps most importantly, chairs must empower others to make positive changes toward harmony and camaraderie. When routinely engrained, a positive climate becomes part of an enduring culture of support. Smith and Costello describe the need for all individuals to recognize burnout and build a judgment-free climate. ${ }^{33}$

Decision-making, best practices, academic governance, and creation of positive workplace climate should be guided by the literature. The academy must rely on credible, peer-reviewed literature sources, as well as our own scientific inquiries. There are a plethora of well-designed, peer-reviewed studies on burnout and related worklife issues in the academic environment. Sabagh et al. remind us that a scholarly approach to the antecedents, correlates, and ramifications of burnout, based on evidence, will find us with the most effective and comprehensive strategies. ${ }^{34}$

\section{Ways Forward in Mitigating Burnout}

Faculty burnout is all too common, yet the very notion is often disregarded among scholars in higher education. Perhaps there is an assumption that the autonomy afforded to faculty could never result in depersonalization. ${ }^{35}$ To mitigate burnout, this commentary calls for scholarly consideration to policies that promote effective communication, strong organizational culture, and supportive work environments. More research is needed to precisely describe communication that connotes reassurance of worth. In the meantime, there have been studies on support at the institutional level. Institutional support can energize faculty productivity. Support can arise from formal means, such as mentoring programs, as well as informal methods, such as the infectious spread of gratitude. Support also comes from clarity in expectations, following through on promises, and the challenging task of providing equitable praise and rewards for faculty with different job responsibilities. ${ }^{36}$ Supportive climates are guided both by common sense and literature-driven evidence of best practices that are sometimes overlooked. In our own respective areas of specialty (teaching and/or research), we look to the literature and to best evidence to guide our actions. The same procedures and deference should be paid to decisions, policymaking, and day-to-day conduct with colleagues as it pertains to creating a positive workplace environment and mitigating burnout. It will take a collective effort from our academy to make this a reality.

\section{Conflicts of Interest: None \\ Funding/support: None}

\section{References}

1. Kingston-Mann E, Sieber T. (Eds.)Achieving Against the Odds: How Academics Become Teachers of Diverse Students.Philadelphia: Temple University Press; 2001.

2. Padilla MA, ThompsonJN. Burning out faculty at doctoral research universities. Stress Health. 2016;32(5):511-558. doi: 10.1002/smi.2661.

3. Miller A, Taylor S,Bedeian A. Publish or perish: Academic life as management faculty live it. Career Dev Int. 2011;16(5):422445.doi: $10.1108 / 13620431111167751$

4. Newport C. Is email making professors stupid? The Chronicle of Higher Education. Feb 12, 2019. Available at: https://www.chronicle.com/interactives/isemail-making-professors-stupid. Accessed on April 29, 2020.

5. Lounder A, Wagaman C, Kenyon $M$, Levine A, Meekins M, O'Meara KA. Following the cuts: How is the recession affecting faculty work? Lib Educ. 2011;97(1):20-29.

6. Gormley DK, Kennerly. Predictors of turnover intention in nurse faculty. $J$ Nurs Educ. 2011;50(4):190-196. doi: 10.3928/0148483420110214-05.

7. El-Ibiary SY, Yam L, Lee KC. Assessment of burnout and associated risk factors among pharmacy practice faculty in the United States. Am J Pharm Educ. 2017;81(4): Article 75. doi: 10.5688/ajpe81475.

8. Prescott WA. Facilitating advance of clinical track faculty. Am J Pharm Educ. 84(5): Article 7910.doi: 10.5688/ajpe7910. 
9. Chung KC, Song JW, Kim HM, et al. Predictors of job satisfaction among academic faculty members: Do instruction and clinical staff differ? Med Educ. 2010;44:985-995. doi: 10.1111/j.13652923.2010.03766.x.

10. Clubbs BH. Faculty Burnout and Its Relationship to Social and Institutional Support [dissertation]. Columbia: University of Missouri; 2020.

11. Persky AM. Intellectual self-doubt and how to get out of it. Am J Pharm Educ. 2018;82(2): Article 6990. doi: 10.5688/ajpe6990.

12. Haizlein J, May N, Scholing J, Williams A, Plews-Ogan $M$. The negativity bias, medication education, and the culture of academic medicine: Why culture change is hard. Acad Med. 2012;87(9):1205-1209. doi: 10.1097/ACM.0b013e3182628f03.

13. Lee KC, Fairman KA, El-Ibiary SY. Item analysis of emotional exhaustion in pharmacy practice faculty. Curr Pharm Teach Learn. 2020;12:504-507. doi: 10.1016/j.cptl.2020.01.003.

14. Maslach C, Shaufeli WB, Leiter MP. Job burnout. Ann Rev Psychol. 2001;52:397-402. doi: 10.1146/annurev.psych.52.1.397.

15. Bruce SP. Recognizing stress and avoiding burnout. Curr Pharm Teach Learn. 2009;1(1):57-64.doi: 10.1016/j.cptl.2009.05.008.

16. Darbishire $P$, Isaacs AN, Miller ML. Faculty burnout in pharmacy education. Am J Pharm Educ. 2020;84(2): Article 7925. Doi: 10.5688/ajpe7925.

17. Conklin MH, Desselle SP. Job turnover intentions among pharmacy faculty.Am J Pharm Educ. 2007;71(4): Article 62. doi: 10.5688/aj710462.

18. Cutrona CE, Russell, DW. The provisions of social relationships and adaptation to stress. In: Jones WH Perlman D, eds. Advances in Personal Relationships. A Research Annual. Greenwich, CT: JAI Press; 1987:3767.

19. Ravasi D, Schultz M. Responding to organizational identity threats: Exploring the role of organizational culture. Aca Manage J 2006;49:433-58. doi: 10.5465/amj.2006.21794663.

20. Desselle S, Rosenthal M, Holmes ER, Andrews B, et al. Components of a measure to describe organizational culture in academic pharmacy. Am J Pharm Educ. 2017;81(10): Article 6022. doi: 10.5688/ajpe6022.

21. Fabio A, Palazzeschi L, Bucci O. Frontiers Psychol. Gratitude in organizations: A contribution for health organizational contexts. 2017;17(Nov17). doi:10.3389/fpsyg.2017.02025/.

22. Bloch $\mathrm{C}$. Managing the emotions of competition and recognition in academia. Sociological Rev. 2002;50(S2):113-131. doi: 10.1111/j.1467954X.2002.tb03594.x.
23. Desselle SP, Semsick GR. Identification and development of items comprising organizational citizenship behaviors among pharmacy faculty. Am J Pharm Educ. 2016;80(10): Article 168.doi: 10.5688/ajpe8010168.

24. Hammer DP, Bynum LA, Carter J, Hagemeier NE, et al. Revisiting faculty citizenship. Am J Pharm Educ. 2019;83(4): Article 7378. doi: 10.5688/ajpe7378.

25. Gochhayat J, Giri VN, Domodar S. Influence of organizational culture on organizational effectiveness: The mediating role of organizational communication. Global Bus Rev. 2017;18(3):691702.doi: 10.1177/0972150917692185.

26. Rahim ARA, Noranee $S$, Othman $K$, et al. Organisation restructuring: The influence of interpersonal conflict, anomie, and trust in management on counterproductive work behavior. Int/ J Manage Sustain. 2018;7(2):83-92. doi: 10.18488/journal.11.2018.72.83.92.

27. Baker B, DiPiro JT. Evaluation of a structured onboarding process and tool for faculty members in a school of pharmacy. Am J Pharm Educ. 2019;83(6): Article 7100. doi: 10.5688/ajpe7100.

28. Peirce GL, Desselle SP, Draugalis JR, Spies AR, et al. Identifying psychological contract breaches to guide faculty recruitment, retention, and development. $A m$ J Pharm Educ. 2012;76(6): Article 108. doi: 10.5688/ajpe766108.

29. Razzaghian M, Ghani U. Breach of psychological contract breach and burnout: Is there a link? Bus Econ Rev. 2015;7(1):19-40.

30. McDowell JM, Singell LD, Stater M. On (and off) the hot seat: An analysis of entry into and out of uiversity administration. Ind Labor Relat Rev. 2011;64(5):889909. doi: 10.1177/001979391106400503.

31. Fisher M. Being chair: A 12-step program for medical school chairs. Int J Med Educ. 2011;2:147-151. doi: 10.5116/ijme.4ece.862d.

32. Willett CG. Reflections from a chair: Leadership of a clinical department at an academic medical center. Cancer. 2015;121:3795-3798. doi: 10.1002/cncr.29588.

33. Smith C, Costello T. The individual's role in maintaining a positive climate. Curr Pharm Teach Learn. 2020;12:496-498.

34. Sabagh Z, Hall NC, Saroyan A. Antecedents, correlates and consequences of faculty burnout. Educ Res. 2018;60(2):131-156. doi: 10.1080/00131881.2018.1461573.

35. Minter RL. Faculty burnout. Contemp Issues Educ Res. 2009;2(2):1-8.

36. Shah DT. Restoring faculty vitality in academic medicine when burnout threatens. Acad Med. 2018;93(7):979-984. doi: 10.1097/ACM.0000000000002013. 